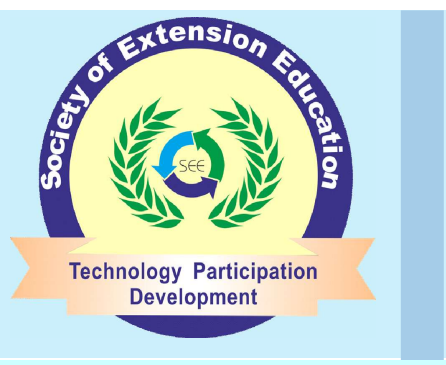

Research Note

\section{Indian Research Journal of Extension Education}

ISSN: 0972-2181 (Print), 0976-1071 (Online)

NAAS Rating : $\mathbf{5 . 2 2}$

Journal homepage: seea.org.in

https://doi.org/10.54986/irjee/2022/jan

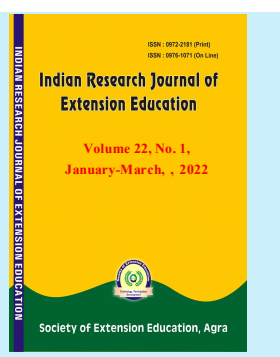

mar/128-130

\title{
Effect of COVID-19 on Socio-economic Status of Entrepreneurs Engaged in Mithila painting
}

\author{
Aparna Kumari ${ }^{1}$ and Rupal Babel ${ }^{2}$ \\ 1. PG Scholar, 2. Asstt. Prof. (Textile and Apparel Designing), CCASc., MPUAT, Udaipur, Rajasthan, \\ Corresponding author e-mail : aparnapandeypusa1995@gmail.com \\ Paper Received on September 23, 2021, Accepted on Novembe 29, 2021 and Published Online on January 01, 2022
}

\begin{abstract}
Mithila painting is a business or source of income of the artist around the Mahbubani district of northern Bihar. Livelihood of these people depend on this painting but during COVID-19 pandemic these artists faced many troubles because all shops were closed due to the lockdown and tourists could not visit here, so it worstly affected their selling of products. The socioeconomic status of entrepreneur is combination of economic and sociology that measure total work experience of an individual or whole family income and social position in community. High socioeconomic status enhances the social standing of entrepreneur in community. The activity of entrepreneur depends on economic, social and psychological factors. A structured questionnaire method was used for collection information from Mithila's painting professional artist and specialist. The study was carried out in Madhubani district of Bihar. For the analysis, a total of 60 samples of female were taken from 2 blocks i.e. Rahika and Rajnagar of Madhubani district. Results of the research investigation are showed that Majority of respondents have significant changed in their family occupation, ownership of fixed assets, farm assets and annual income between before and during crisis. Finding revealed that Majority (83.33\%) of respondents diverted Mithila painting in mask making during pandemic crisis for employment generation.
\end{abstract}

Keyword: Covid-19 pandemic crisis; Socio-economic status; Mithila painting.

India has a diverse range of culture and traditions that are portrayed from various conventional arts and crafts. Indian folk art has its unique style which includes ethnic and simple as well as colourful and vibrant elegance at the same time describing the rich heritage. Now-a-days Indian folk art has reached the international market, got appreciated due to its aesthetic sensibility and authenticity. Skilled abilities of folk artisans express religious sentiments and socio-cultural traditions that attract attention of human mind and capture the heart of people. It has thus made significant contributions in Indian economy through trade and promotes tourism as well (Sharma, 2015). Madhubani is known as heartland of Mithila, the ancient kingdom of Mithilanchal, which was extended from Nepal in north to Darbhanga in south, from Janki's Birth place (Sitamarhi) in west to Supaul in east. Madhubani painting, the famous folk art of Mithila region, acquired the international fame due to their recognition. Each region has self- expression. The people of Mithila express their feelings through this painting. This is the most sophisticated of all popular paintings in India not only elegantly but also won critical acclaim. These are created by women artists of Mithila region, mainly comprising housewives. Initially, the 
paintings were created by women of Mithila for decorating wall and floor of house on every religious and social occasion but gradually it improved the socioeconomic status of women in the society by generating income and employment opportunities. This traditional art establishes a deep relationship in art and culture other than elegant deliberation (Agarwal, 2015).

Livelihood of the entrepreneurs depend on this painting but during COVID-19 pandemic artists faced many troubles because all shops were closed due to the lockdown and tourists could not visit here, so it worstly affected their selling of products. In that critical situation the artist had no any work to earn money, so they remained unemployed. After some time they thought a creative idea to do Mithila painting on mask to generate their income so it gave a new opportunity. Keeping this view in mind the present study was undertaken with the following objective - To study the activities of entrepreneurs during pandemic crisis.

\section{METHODOLOGY}

A structured questionnaire method was used for collection information from Mithila's painting professional artist and specialist. The study was carried out in Madhubani district of Bihar. For the analysis, a total of 60 samples of female were taken from 2 blocks i.e. Rahika and Rajnagar of Madhubani district. A purposive sampling technique was used for the selection of sample. On the basis of preview studies and discussion with expert related to this field independent and dependent variable (age, cast, marital status, and occupation). Effect of COVID-19 on socioeconomic status of entrepreneurs revealed that out of 11 variables which were subjected to analysis.

\section{RESULT AND DISCUSSION}

The data of Table 1 showed that majority of respondents, $(50 \%)$ belonged to young age group, belonging to upper cast (65\%), Majority of respondents married (75\%), Majority of respondents were non-wage earner $(60 \%)$.

Activities of entrepreneurs during crisis : It is evident from the Table 2 that 83.33 per cent of respondents diverted Mithila painting in mask making during pandemic crisis for employment generation. It is evident from the Table 3 that majority of respondents $(50.00 \%)$ were motivated to divert the Mithila painting in mask making by friends/neighbours, 20.00 per cent by government organization, 9.85 per cent by family member and only 5.65 per cent by relatives. It is evident from the Table 2 . that majority of respondents $(53.33 \%)$ were creating mask for self - employment, 18.00 per cent for other

Table 1. Background Information of women entrepreneurs

\begin{tabular}{llll}
\hline Variables & Category & No. & $\%$ \\
\hline Age & 18 to 30 years & 30 & 50 \\
Caste & Upper cast & 39 & 65 \\
Marital Status & Married & 45 & 75 \\
Occupation & Non.-Wage earner & 36 & 60 \\
\hline
\end{tabular}

Table 2. Activities of entrepreneurs during crisis

\begin{tabular}{lllllll}
\hline Statement & \multicolumn{3}{l}{ Rahika(n=30) } & \multicolumn{3}{l}{ Rajnagar(n=30) } \\
& No. & $\%$ & Total $(\mathrm{n}=60)$ \\
& & No. & No. & $\%$ \\
\hline Have you diverted mithila painting in mask making & 25 & 83.33 & 25 & 83.33 & 50 & 83.33 \\
Who motivated you to divert the Mithila painting in mask making & & & & & & \\
Family member & 2 & 6.66 & 3 & 10.00 & 5 & $(9.85)$ \\
Relatives & 1 & 3.33 & 2 & 6.66 & 3 & $(5.65)$ \\
Friends/neighbours & 16 & 53.33 & 14 & 46.66 & 30 & 50.00 \\
Govt. organization & 6 & 20.00 & 6 & 20.0 & 12 & 20.00 \\
Reason for creating mask & & & & & & \\
Self- employment & 15 & 50.00 & 17 & 56.67 & 32 & 53.33 \\
Saving habit & 1 & 3.33 & 3 & 10.00 & 4 & 6.66 \\
Availing loan & 2 & 6.66 & 1 & 3.33 & 3 & $(5.79)$ \\
Others reason & 7 & 23.33 & 4 & 13.33 & 11 & 18.00 \\
Earned equal money as in painting & 5 & 16.66 & 5 & 16.66 & 10 & 16.66 \\
Monthly income from your business in sufficient fulfilment of family need & 7 & 23.33 & 7 & 23.33 & 13 & 23.33 \\
\hline
\end{tabular}


reason, 6.66 per cent for saving habit and only 5.79 per cent for availing loan. It is clear from the table that only 23.33 per cent respondents were sufficient fulfilment of family need through their monthly income and 16.66 per cent respondents were earned equal money as in painting.

\section{CONCLUSION}

COVID-19 and lockdown have adversely influenced the global market regarding disturbance of supply chains, labour crisis due to migration and also altered consumer behaviour resulting into loss and financial crisis to the business world. The study was carried out in Madhubani district of Bihar. For the analysis, a total of 60 samples of female were taken from 2 blocks i.e. Rahika and Rajnagar of Madhubani district. From the effect of COVID-19 on socioeconomic status of entrepreneurs, it was found that there was no significant difference in family structure, education of respondents in before and during pandemic situation. Majority of respondents have significant changed in their family occupation, ownership of fixed assets, farm assets and annual income between before and during crisis.
Most of the respondents have less significant changed in distinctive features i.e. transport, source of information used by respondents before and during crisis. From activities of entrepreneur, it was found that majority (83.33\%) of respondent's diverted Mithila painting in mask making during pandemic crisis for employment generation. Most of the respondents were motivated to divert Mithila painting in mask making by friends/ neighbours. Majority of respondents were creating mask for self-employment and minimum number of respondents were earned equal money as in painting, Monthly income from your business in sufficient fulfilment of family need.

Lastly, it can be concluded that there was significant difference in economic status of women entrepreneurs. The investigation also indicates that majority of respondents divert Mithila painting in mask making during pandemic crisis for livelihood.

\section{CONFLICTS OF INTEREST}

The authors declare that they have no conflicts of interest.

\section{REFERENCE}

Agarwal, R. (2015). Madhubani Painting: Women Dominated Folk Art. Intl.J. of Applied Res., 1(11) : 736-738.

Lokhande, A.M. (2015). A study of socio- economic background of entrepreneurs from semi- urban centers in Maharashtra. Professionals center for Busi. Res., 02 (3):11-18.

Sharma, E., Paul, S. (2015). Adoption of Indian folk painting for designing and digital printing of apparels using computer added designing. Intl. J. of Applied Res., 1(9): 989-995. 